\title{
Study of Oxide Nanoparticles as Additives for Vegetable Lubricants
}

\author{
Marinalva Ferreira Trajano, Edja Iandeyara Freitas Moura, \\ Kandice Suane Barros Ribeiro, Salete Martins Alves* \\ University Federal do Rio Grande do Norte-UFRN, Campus Universitário Lagoa Nova, \\ CEP 59072-970, Natal, RN, Brazil
}

Received: July 1, 2013; Revised: September 11, 2014

\begin{abstract}
Currently, vegetable oils have been studied as biolubricants in order to reach new environmental standards. Besides being non-renewable, mineral oils from petroleum bring consequences to the environment due to its low biodegradability. Thus, the aim of this work is to develop a biolubricant and to add oxide nanoparticles $(\mathrm{ZnO}$ and $\mathrm{CuO})$ in order to improve abrasion resistance and friction. This product must be biodegradable and has better performance under boundary lubrication. The methodology consisted of the synthesis of biolubricants using vegetable oils (soybean and sunflower) by epoxidation reaction. The tribological performance was evaluated by HFRR (High Frequency Reciprocating Rig). The developed biolubricants showed good tribological properties besides being more adapted to the environment. Also, it was possible to verify that biolubricants without additives are slightly more tribologically effective than lubricants with additives.
\end{abstract}

Keywords: nanoparticles of oxides, biolubricants, wear

\section{Introduction}

Most lubricants available on the market are mineralbased and synthetics. These lubricant oils are effective in lubrication but they are not environmentally friendly. Due to serious environmental impacts caused by them, new alternatives have been researched to replace mineral based lubricants and synthetic bases by the renewable ones that are less harmful to the environment.

One of these new alternatives is the chemically modified vegetable oils due to their non-toxic and renewable character and their good lubrication properties ${ }^{1}$. In addition, the vegetable oils are important for developing new lubricants, which meet the current economic needs of the country and demands for improved quality of life and protection of the environment ${ }^{2}$.

The lubricant bases are selected according to their ability to: form a protective film on sliding parts; resist high temperature and oxygen presence, which change their properties; support mechanical loads, without changing its lubricity; remove heat from the internal components of the equipment ${ }^{3}$. In order to improve performance characteristics of lubricants, some chemical components are added, they are called additives. The most common used additives are antioxidants and extreme pressure agents (EP). EP additive reacts chemically with the metal surface forming a film which reduces friction. The conventional EP additives are sulfur, chlorine and phosphorous. These EP additives prevent high wear caused by contact between metal to metal under high loads ${ }^{4}$. However, these additives are showing some restrictions on its use due to their environmental impacts.

*e-mail: saletealves@ect.ufrn.br
In this context, the oxide nanoparticles appear as an important alternative to replace the conventional extreme pressure additives, as they can minimize friction and wear, making the lubricants more environmentally friendly. According to Xue et al. ${ }^{4}$, the results of several studies show that inorganic nanoparticles can be deposited on the contact surface and improve the tribological properties of the base oil. It was also noted by Xue et al. ${ }^{4}$ and Dong et al. ${ }^{5}$ that nanoparticles exhibit good characteristics of adhesion and reduction of wear, even at concentrations below $2 \mathrm{wt} . \%$.

The objective of this study was to develop a biolubricant and to add nanoparticles of copper oxide and zinc as EP additive, in order to improve their tribological performance under boundary lubrication.

\section{Experimental}

The biolubricant was synthesized by an epoxidation reaction which is applied to compounds that contain unsaturated bonds in the carbon chains. This reaction transforms unsaturated bonds into oxirane rings.

The required amount of Soybean and Sunflower oil was placed in the reactor, along with the suitable amount of acetic acid, $4 \%$ sulfuric acid (catalyst) and $35 \%$ aqueous hydrogen peroxide. The chosen molar ratio of hydrogen peroxide/acetic acid/double bonds of the oils was 20/2/1. The reagents were mixed into a well-stirred, round-bottom glass reactor kept at $50^{\circ} \mathrm{C}$. The reaction time was five hours. The mixtures were washed with distilled water until the complete removal of acids from the organic phase was achieved. The modified oil was washed with $\mathrm{NaHCO}_{3}$ (10 wt. \%) to neutralize the $\mathrm{pH}$. After that, the biolubricants were dried at $90-100^{\circ} \mathrm{C}$ for $4 \mathrm{~h}$. 
The epoxidized oils were analyzed in terms of viscosity, density, acidity and Iodine value. The iodine value was obtained using the Wijs method according to AOCSCd1-25. This value indentifies the unsaturation of oils and fats in terms of centigrams of iodine absorbed per gram of fats $(\%$ iodine absorbed $)^{6}$. Density was measure by pycnometer and viscosity was determined by Brookfield RS2000 rheometer at 40 and $100^{\circ} \mathrm{C}$. With these viscosities values, the viscosity index (VI) was determined following the standard ASTM 2270 . The acidity was also measured following the AOCS Cd 3d-6.

Nanoparticles of zinc and copper oxides were used as EP additives, with an average crystallite size of 11.71 and $4.35 \mathrm{~nm}$, respectively, and both nanoparticles having spherical shapes. The nanoparticles $(\mathrm{CuO}$ and $\mathrm{ZnO})$ were separately dispersed in the lubricant in concentration of $0.5 \mathrm{wt} \%$, using an ultrasonic probe for $30 \mathrm{~min}$. The concentration of nanoparticles was chosen based on literature review ${ }^{7,8}$, according to these authors the $0,5 \%$ has the better concentration of $\mathrm{CuO}$ and $\mathrm{ZnO}$ nanoparticle in oil base. Also some screen tests were carried out and the $0,5 \%$ wt of $\mathrm{CuO}$ and $\mathrm{ZnO}$ showed better results.

Tribological performance tests were evaluated in HFRR (High Frequency Reciprocating Rig). This test consists of a ball-on-disk contact to measure the friction and wear under boundary lubrication conditions using a highly stressed ball-on-disk contact. A hard steel ball (570-750 HV) of $6.0 \mathrm{~mm}$ diameter slides in reciprocating movement on a softer steel disk (190-210HV) of $10 \mathrm{~mm}$ diameter under the fully submerged oil condition. During the friction test, the coefficient was measured by a piezoelectric force transducer and the formation of electrically insulating films at the sliding contact was measured by the ECR (Electrical Contact Resistance) technique. The parameters used were shown in Table 1.

The tribological pairs (ball and disc) were cleaned by immersion in toluene for 7 minutes, dried with hot air, and again immersed for 3 minutes in acetone.

\section{Results and Discussion}

Firstly, physico-chemical analysis of biolubricants (density, iodine value, acidity, viscosity and VI) are presented and discussed. These properties are very important to evaluate the quality of these lubricants. In Table 2, the physico-chemical properties of soybean and sunflower biolubricants are shown.
According to Anvisa ${ }^{9}$, the density of soybean and sunflower oils should be between 0,9150-0.9200 g/ $\mathrm{cm}^{3}$ at temperature of $25{ }^{\circ} \mathrm{C}$. Thus, for sunflower biolubricant, it was observed that its density is according to expected values for the same refined commercial oil, but soybean biolubricant showed a little more increase in density than the commercial refined soybean oil.

The efficiency of epoxidation reaction was determined by iodine index, which is the number of centigrams of iodine absorbed per one gram of fat (unsaturation). The absorption of iodine determines the amount of double bonds in fatty acids. High iodine index shows that more unsaturated bonds are present in the oil or fat analyzed. As in the epoxidation reaction, the unsaturated bonds are replaced by oxirane ring, the iodine index tends to be very low due to the lack of unsaturated bonds. As observed in Table 2, the iodine for biolubricants were low, indicating the efficiency of epoxidation, considering the iodine index for commercial oils refined soybean and sunflower are (120 to $141 \mathrm{~g} \mathrm{I}_{2} / 100 \mathrm{~g}$ ) and (110 to $143 \mathrm{~g} \mathrm{I}_{2} / 100 \mathrm{~g}$ ), respectively ${ }^{10}$. And for a biolubricant, the iodine value was around 1.8 to $2 \mathrm{~g} \mathrm{I}_{2} / 100 \mathrm{~g}$ fat, which is the efficient percentage of epoxidation in the studies ${ }^{10}$.

The acidity of biolubricants (Table 2) showed values below the values for the refined commercial oils (up to $3 \%$ for soybean and up to $2 \%$ sunflower oil $)^{11,12}$. This is very good because a high acidity in biolubricants is not recommended due to the occurrence of oxidation, which can accelerate wear and rust formation and corrosion.

The viscosity for biolubricants showed higher values (Table 2) than those of commercial vegetable oils (at $40^{\circ} \mathrm{C}$ : Soybean - $31.9 \mathrm{cSt}$ and sunflower $-31.6 \mathrm{cSt}$, and $100{ }^{\circ} \mathrm{C}$ : soybean and sunflower $-5.1 \mathrm{cSt})^{13}$, one must consider that the viscosity is the most important lubrication property. Normally, the vegetable based lubricant shows high viscosity, making it more suitable for boundary lubrication.

VI indicates changes in viscosity with variations in temperature. A high VI indicates small changes in temperature, whereas a low VI indicates high changes in temperature. According to Mobarak et al. ${ }^{14}$ vegetable oil-based biolubricants have higher VI than mineral oils (around 100), which ensures that biolubricants remain effective even at high temperatures by maintaining the thickness of the oil film. Biolubricants based on epoxidized oils exhibit VI around 145 (Table 2) and they are suitable for a wide temperature range.

Table 1. Parameters used in the equipment High Frequency Reciprocating Rig.

\begin{tabular}{ccccc}
\hline \multicolumn{5}{c}{ Parameters used in the equipment High Frequency Reciprocating Rig } \\
\hline Frequency & Load & Stroke Length & Temperature & Time \\
\hline $20 \mathrm{~Hz}$ & $10 \mathrm{~N}$ & $1 \mathrm{~mm}$ & $50^{\circ} \mathrm{C}$ & $60 \mathrm{~min}$ \\
\hline
\end{tabular}

Table 2. Physico-chemical characteristics of soybean and sunflower biolubricants.

\begin{tabular}{|c|c|c|c|c|c|}
\hline $\begin{array}{l}\text { Bio-lubricants / } \\
\text { PPC* }\end{array}$ & $\begin{array}{c}\text { Density }\left(\mathrm{g} / \mathrm{cm}^{3}\right) \text { a } \\
25^{\circ} \mathrm{C}\end{array}$ & $\begin{array}{l}\text { Iodine Index (g de } \\
\mathrm{I}_{2} / 100 \mathrm{~g} \text { of fat) }\end{array}$ & $\begin{array}{c}\text { Acidity (\% mg } \\
\mathrm{NaOH})\end{array}$ & $\begin{array}{c}\text { Viscosity at } 40^{\circ} \mathrm{C} / \\
100^{\circ} \mathrm{C} \text { (CSt) }\end{array}$ & Viscosity Index \\
\hline Soybean & 0.9604 & 3.4 & 1.0968 & $144.72 / 28.08$ & 145 \\
\hline Sunflower & 0.9197 & 4.1 & 0.8981 & $151.2 / 28.08$ & 144 \\
\hline
\end{tabular}

*Physico-Chemical Properties. 
Besides the lubricants showing good physical-chemical properties, it is necessary that they exhibit good performance in tribological tests. The performance of lubricant without and with additives was evaluated though of HFRR test. This tribological performance was evaluated based on the friction coefficients and percentage of films formed.

The friction coefficients for all lubricants are displayed in Figure 1. The friction coefficient shows low values for epoxidized oils without additives. The addition of oxides nanoparticles show a little increase of the coefficient of friction in these cases, the nanoparticles did not act as antiwear additive. This fact occurs probably because the nanoparticles became as the third body increasing friction and wear. According to Chiñas-Castillo and Spikes ${ }^{15}$, nanoparticles have a harmful effect in some cases. It is also important to consider the chemistry nature of biolubrificants, its polarity promotes the adsorption on metal surface resulting in reduction of friction and wear. They form a thin layer that improves the metal-to-metal separation. Thus, if the nanoparticles cannot penetrate in the contact area, their deposition on metal surface will be not efficient, increasing the wear.

Some studies reported in the literature such as Hernández Battez et al. ${ }^{7,8}$ and Qiuhong and Xifeng ${ }^{16}$ exhibit very satisfactory results when nanooxides have been used as EP additives in mineral and synthetic oil, reducing friction and wear resistance. However, this work shows that the nanoxides studied do not improve performance of biolubrificants. This suggests that EP action of nanooxides depends on the base lubricant.

The behavior of film formation is observed in Figure 2 for biolubricants with and without additives. The surface coverage, caused by generation and removal of surface films, was measured under boundary lubrication conditions with a steel ball sliding against a steel disk by means of the ECR. According to Viesca et al. ${ }^{17}$, the electrical resistance

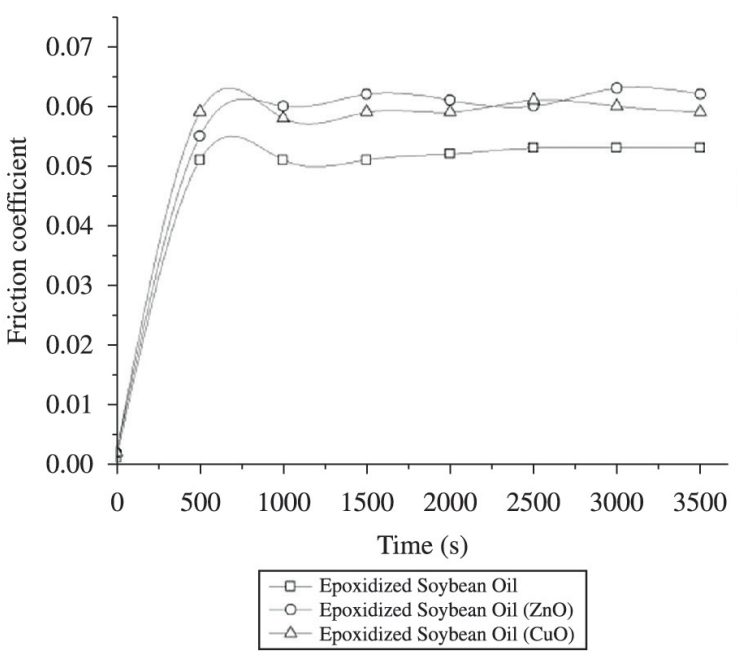

(a)

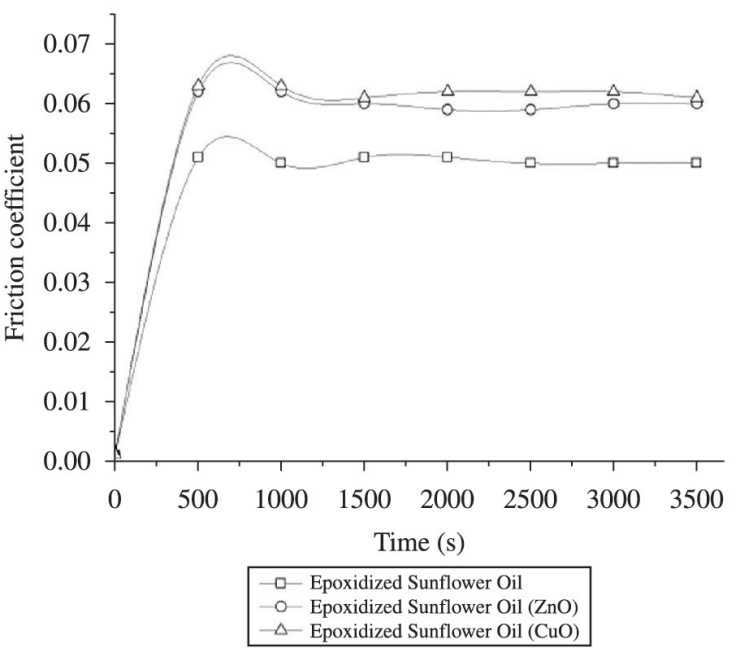

(b)

Figure 1. Coefficient of friction behavior for biolubricants: a) epoxidized soybean oil and b) epoxidized sunflower oil.

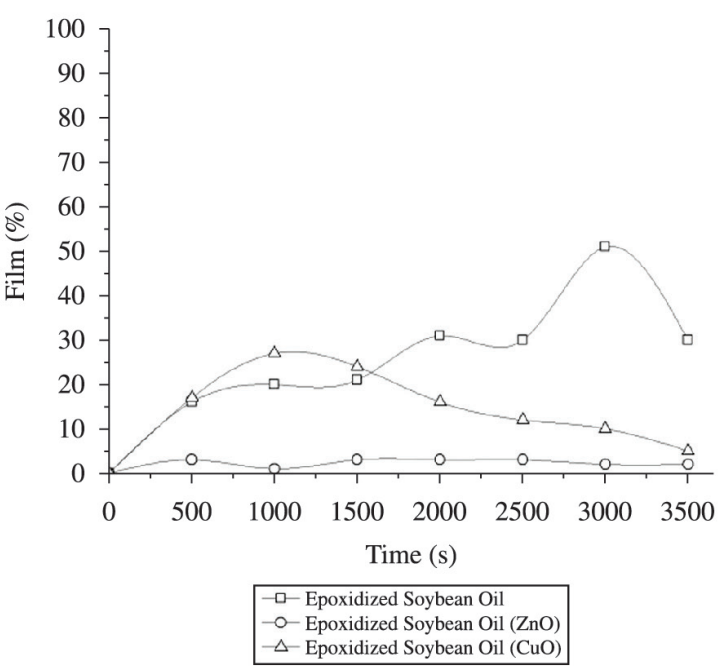

(a)

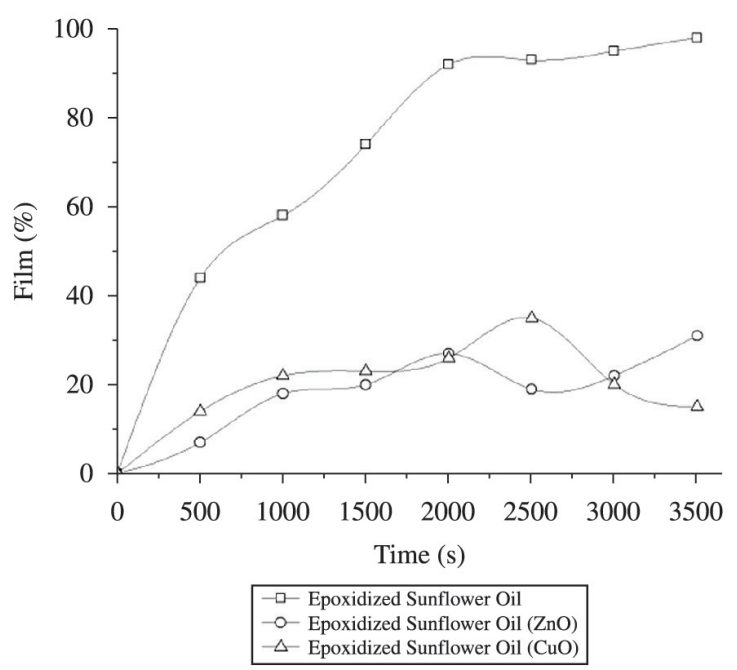

(b)

Figure 2. Film formation behavior for biolubricants: a) epoxidized soybean oil and b) epoxidized sunflower oil. 


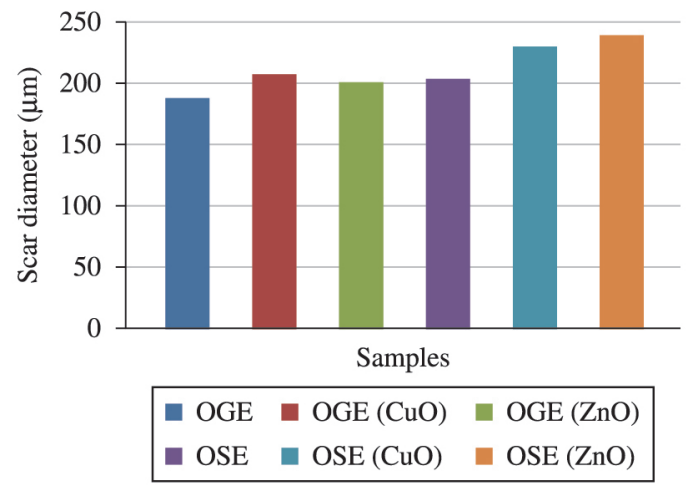

Figure 3. Wear Sphere observed in lubricants analyzed. OSE (epoxidized soybean oil); OSE $(\mathrm{CuO})$ (epoxidized soybean oil with Copper Oxide Nanoparticle); OSE ( $\mathrm{ZnO}$ ) (epoxidized soybean oil with Zinc Oxide Nanoparticle); OGE (Sunflower Oil Epoxidized); OGE $(\mathrm{CuO})$ (Sunflower Oil with Copper Oxide Nanoparticles); OGE (ZnO) (Sunflower Oil Epoxidized with Nanoparticles of Zinc Oxide).

between the two contacting surfaces gives an idea of the amount of direct metal-metal contact. Although deducting of the contact area by the resistance value is not obvious, the measured values are often used for qualitative analysis. The film formation is strongly influenced by oil base and EP additive.

The sunflower biolubricant with $\mathrm{CuO}$ and $\mathrm{ZnO}$ nanoparticles shows similar behavior of film formation around $20 \%$, while biolubricant without additive showed better performance around 90\% after 2000 seconds of wear test. The same behavior is not observed with soybean lubricant. When $\mathrm{ZnO}$ was added to lubricant, the percentage of film formation was reduced drastically, and soybean biolubricant with $\mathrm{CuO}$ did not maintain the film throughout the test. This different behavior is due to polarity of biolubricants. This may be because the sunflower polarity is higher than soybean polarity, resulting in higher adsorption on metal surface. The different results for vegetable base lubricant with oxide nanoparticles could be associated to third body behavior of these oxides that increase the friction and reduce the electrical conductivity between specimen surfaces (less ECR). The sunflower pure oil presents excellent film formation ability. According to Hutching ${ }^{18}$, vegetable oil, naturally, contains molecular species with boundary lubrication properties (like acid oleic). It is also necessary to consider that sunflower oil has high polarity which increases the adhesion to metal surface.

\section{References}

1. Pettersson A. High-performance base fluids for environmentally adapted lubricants. Tribology International. 2007; 40(4):638645. http://dx.doi.org/10.1016/j.triboint.2005.11.016.

2. Nunes MRS, Martinelli M and Pedroso MM. Epoxidação do óleo de mamona e derivados empregando o sistema catalítico VO (acac)2/TBHP. Quimica Nova. 2008; 31(4):818-821. http:// dx.doi.org/10.1590/S0100-40422008000400021.

3. Dowson D. History of Tribology. London: Professional Engineering Publishing Ltd; 1998.
Besides friction coefficient analysis, the wear scar diameter (WSD) was evaluated in order to analyze the wear on the ball during the contact. The results shown in Figure 3, demonstrate the trend observed for the coefficient of friction.

The addition of nanoparticles of oxides $(\mathrm{CuO}$ and $\mathrm{ZnO})$ increases the wear scar diameter observed on the ball. This increase is more significant for soybean biolubricant when nanoparticles are added. On the other hand, a little increase was observed with nanoparticle addition in sunflower biolubricant. Another interesting observation is the different behavior of nanoparticles depending on vegetable oil base. The high wear was observed for the soybean lubricant with $\mathrm{ZnO}$ nanoparticles $(248 \mathrm{~mm})$, while for sunflower lubricant, the higher wear was found with addition of $\mathrm{CuO}$ nanoparticles $(210 \mathrm{~mm})$. The epoxidized sunflower oils and additives obtained less wear, mainly sunflower biolubricant without additives with approximately 180 micrometers.

\section{Conclusions}

This current work has focused on the synthesis of biolubricant from epoxidized vegetable oil and evaluating the addition of oxides nanoparticles in this lubricant. Thus, the following conclusions can be drawn from the results presented above:

- The epoxidized sunflower and soybean oils have properties suitable for the formulation of lubricants, especially for applications operating over a wide temperature range, because of its excellent viscosity index.

- These biolubricants showed good performance in boundary conditions, decreasing friction coefficient and improving film formation on metal surface. However, better performance was observed for epoxidized sunflower oil.

- The oxides nanoparticles when added to epoxidized oil do not exhibit wear and friction reduction as expected by literature. This, probably, occurs due to the excellent adsorption ability of biolubricants on metal surface. Thus, the nanoparticle deposition on surface is hampered and they act as a third body increasing the wear.

\section{Acknowledgements}

The authors wish to express thanks to the National council of scientific and technological development (CNPq) of Brazil, for supporting this work within the framework of the Research of Project CNPq 48069/2011-8.

4. Xue QJ, Liu WM and Zhang ZJ. Friction and wear properties of the surface modified the $\mathrm{TiO} 2$ nanoparticle additive in liquid paraffin n. Wear. 1997; 213(1-2):29-32. http://dx.doi. org/10.1016/S0043-1648(97)00200-7.

5. Dong C, Cao J, Struble EJ and Lipowsky HH. Mechanics of leukocyte deformation and adhesion to endothelium in shear flow. Annals of Biomedical Engineering. 1999; 27(3):298-312. http://dx.doi.org/10.1114/1.143. PMid:10374723

6. Akishino JK. Epoxidation and esterification of oleic acid and vegetable oils. Curitiba: Technological University Federal Paraná; 2010. p. 68-72. Internship Report. 
7. Hernández Battez A, González R, Felgueroso D, Fernández JE, Del Rocío Fernandéz MA, García MA, et al. Wear prevention of nanoparticle suspension behavior under extreme pressure conditions. Wear. 2007; 263(7-12):1568-1574. http://dx.doi. org/10.1016/j.wear.2007.01.093.

8. Hernández Battez A, Fernandez Rico JE, Navas Arias A, Viesca Rodriguez JL, Chou Rodriguez R and Diaz Fernandez JM. The tribological behavior of $\mathrm{ZnO}$ nanoparticles to an additive to PAO6. Wear. 2006; 261(3-4):256-263. http://dx.doi. org/10.1016/j.wear.2005.10.001.

9. Agência Nacional de Vigilância Sanitária-Anvisa. Resolução n. 482, de 23 de setembro de 1999. Diário Oficial da União. 2000 June 20. Available from: <http://www.anvisa.gov.br/legis/ resol/482_99.htm>. Access in: 25/09/2012.

10. Farias M. Synthesis, characterization of catalysts and its activities study on catalytic epoxidation of vegetable oils. [Tese]. Porto Alegre; 2010.

11. Campestre. Óleo de soja: especificações técnicas. São Bernardo do Campo. Available from: <http://www.campestre.com.br/ especificacao_soja.shtml>. Access in: 25/09/2012.

12. Campestre. Óleo de girassol: especificações técnicas. São Bernardo do Campo. Available from: $<$ http://www.campestre. com.br/especificacao_girassol.shtm>. Access in: 25/09/2012.

13. Brock J, Walnut MR, Zakrzevski C, Corazza FC, Corazza ML and Oliveira JV. Experimental measurements of viscosity and thermal conductivity of vegetable oils. Food Science and Technology. 2008; 28(3):564-570.

14. Mobarak HM, Niza Mohamad E, Masjuki HH, Kalam MA, Al Mahmud KAH, Habibullah M, et al. The prospects of biolubricants as alternatives in automotive applications. Renewable \& Sustainable Energy Reviews. 2014; 33:34-43. http://dx.doi.org/10.1016/j.rser.2014.01.062.

15. Chiñas-Castillo $\mathrm{F}$ and Spikes HA. The behaviour of colloidal solid particles in elastohydrodynamic contacts. Tribology Transactions. 2000; 43(3):387-394. http://dx.doi. org/10.1080/10402000008982354.

16. Qiuhong P and Xifeng Z. Synthesis and Tribological Behavior of Oil-Soluble $\mathrm{Cu}$ Nanoparticles as Additive in SF15W/40 Lubricating Oil. Rare Metal Materials and Engineering. 2010; 39(10):1711-1714. http://dx.doi.org/10.1016/S18755372(10)60129-4.

17. Viesca JL, HernÁndez Battez A, González R, Reddyhoff T, Torres Perez A and Spikes HA. Assessing boundary film formation of lubricant additivised with 1-hexyl-3methylimidazolium tetrafluoroborate using ECR as qualitative indicator. Wear. 2010; 269(1-2):112-117. http://dx.doi. org/10.1016/j.wear.2010.03.014.

18. Hutching IM. Tribology: friction and wear of engineering materials. London: Edward Arnold; 1992. 